\title{
PREVALENCE OF DEPRESSION AMONG NEWLY DIAGNOSED MDR TUBERCULOSIS PATIENTS AT THE TIME OF REGISTRATION- AN EXPERIENCE FROM DOTS PLUS CENTRE
}

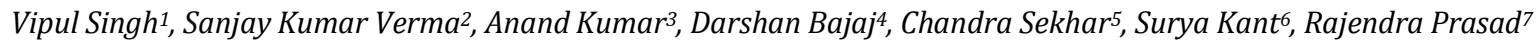 \\ ${ }^{1}$ Associate Professor, Department of Psychiatry, Government Medical College, Kannauj, U. P. \\ ${ }^{2}$ Associate Professor, Department of TB and Respiratory Diseases, Government Medical College, Kannauj, U. P. \\ ${ }^{3}$ Associate Professor and HOD, Department of TB and Respiratory Diseases, GSVM Medical College, Kanpur. \\ ${ }^{4}$ Assistant Professor, Department of Pulmonary Medicine, King George's Medical University, Lucknow, U. P. \\ 5Junior Resident, Department of TB and Respiratory Diseases, GSVM Medical College, Kanpur. \\ ${ }^{6}$ Professor and HOD, Department of Pulmonary Medicine, King George's Medical University, Lucknow, U. P. \\ TProfessor and HOD, Department of Pulmonary Medicine, Era's Lucknow Medical College, Lucknow. U. P.
}

\begin{abstract}
BACKGROUND

MDR tuberculosis remains a leading chronic infection of lung and responsible for significant morbidity and mortality throughout the world and in India also. Depression is also a disorder of major public health importance in terms of its prevalence and the suffering, dysfunction, morbidity and economic burden. Depression and MDR tuberculosis co-exists, because of physical changes from the illness trigger the depression resulting in vicious cycle. So, it is very important to establish the prevalence of depression in MDR tuberculosis. To the best of our knowledge, very little is known about depression in MDR tuberculosis patients.

The objective of this study is to find out the prevalence of depression among newly diagnosed MDR tuberculosis patients before the start of Category-IV treatments.
\end{abstract}

\section{MATERIALS AND METHODS}

This was a cross-sectional study conducted in Department of Respiratory Diseases, GMC, Kannauj (India). A total of 130 MDR-TB patients were included in the study, which were enrolled for treatment in this unit from January 2017 till June 2017 and assessed at the time of registration for depression. Hamilton depression rating scale (HAM-D) was used to assess depression among MDRTB patients.

\section{RESULTS}

One hundred and thirty patients with MDR tuberculosis were enrolled during the study period. There were 93 males (71.5\%) and $37(28.4 \%)$ females. The mean age of study subject was $29.45 \pm 14.49$ years with a male-to-female ratio of $2.5: 1$. Depression was not found in $6(4.62 \%)$ patients, whereas $124(95.3 \%)$ of the study participants were classified as depressive on the HAM-D scale. 65 patients $(50 \%)$ had mild depression, 26 patients $(20 \%)$ had moderate depression and 33 patients $(25.3 \%)$ were diagnosed with severe depression.

\section{CONCLUSION}

Depression is a very important negative factor to treatment adherence and it is important to diagnose and treat depression in time to get the desired results of TB treatment.

\section{KEYWORDS}

Depression, Multi-Drug Resistance, Tuberculosis.

HOW TO CITE THIS ARTICLE: Singh V, Verma SK, Kumar A, et al. Prevalence of depression among newly diagnosed MDR tuberculosis patients at the time of registration- an experience from DOTS plus centre. J. Evolution Med. Dent. Sci. 2018;7(04):519523, DOI: $10.14260 /$ jemds/2018/116

\section{BACKGROUND}

Tuberculosis is a chronic infectious disease caused predominantly by Mycobacterium tuberculosis and India accounts for one-fourth of the global TB burden (i.e. 2.2 million out of 9.6 million new cases annually). ${ }^{1}$

Multi-drug resistant TB (MDR-TB) is defined as M. tuberculosis resistant to isoniazid and rifampicin with or without resistance to other drugs. Data from studies

'Financial or Other Competing Interest': None.

Submission 14-11-2017, Peer Review 07-01-2018,

Acceptance 12-01-2018, Published 22-01-2018.

Corresponding Author:

Dr. Vipul Singh,

Associate Professor

Department of Psychiatry,

Government Medical College, Kannauj, U. P.

E-mail: drvipulsingh@yahoo.co.in

DOI: $10.14260 / \mathrm{jemds} / 2018 / 116$

\section{(c) (1) (8) $\Theta$}

conducted by NIRT (erstwhile TRC) and NTI, have found MDR-TB levels of $1 \%$ to $3 \%$ in new cases and around $12 \%$ in re-treatment cases. ${ }^{2-3}$ RNTCP has recently undertaken three community-based state level drug resistance surveillance (DRS) studies in Gujarat, Maharashtra and Andhra Pradesh. These surveys have been conducted as per a common generic protocol based on internationally accepted methodology and have estimated the prevalence of MDR-TB to be about 3\% in new cases and $12 \%-17 \%$ in re-treatment cases. ${ }^{4}$

Common mental disorders (CMDs) including depression, anxiety disorders and substance use disorders are a huge burden affecting nearly $10.0 \%$ of the population..$^{5}$ Depression, among the other psychiatric morbidities, has a lifetime prevalence of $10 \% .{ }^{6}$ It has a point prevalence of $2.3 \%$ to $4.9 \%$ in the general population. ${ }^{7}$ Comorbidity of TB and depression is common. ${ }^{8-9}$ The prevalence of comorbid depression with a chronic physical condition ranges between $25 \%$ and $33 \%$. The risk increases with the severity of the illness 10 and this 
frequently presents a management challenge to physicians. The cause of the comorbidity remains unclear. Chronic psychogenic and somatic pain, frequent hospital admissions and hospital dependency are factors related to depression among persons with chronic pulmonary diseases.11 Furthermore, it has been reported that $30 \%$ of patients with moderate respiratory failure have depression. ${ }^{12}$

Psychiatric complications are commonly associated with MDR-TB, both at baseline and due to Second Line Drug (SLD) use. The frequency of psychiatric disorders associated with MDR-TB treatment varies from $6.2 \%$ to $22 \% .{ }^{13-18}$

The baseline mental health characteristics of patients may determine the development of subsequent psychiatric conditions. A mental health assessment before MDR-TB treatment initiation may thus assist in better management of psychiatric illnesses and improve treatment outcomes.15,19

Depression may also adversely affect the compliance to treatment and result in default which in turn may have serious consequences of treatment failure and further extension in drug resistance. Depression may be a very important negative factor to treatment adherence for patients on tuberculosis treatment. ${ }^{20-21}$

Despite the high prevalence of MDR-TB in India, there is a dearth of information on the prevalence of depression among patients suffering from MDR-TB, hence the justification for this study.

\section{MATERIALS AND METHODS \\ Study Design}

This was a cross-sectional study conducted to describe frequency of depression and other associated factors among MDR-TB patients at baseline (at the time of registration for MDR-TB treatment).

\section{Subjects}

From a total of 195 patients, only 130 MDR-TB patients were interviewed during the study period, which were enrolled for treatment in this unit from January 2017 to April 2017. Convenient sampling technique was used for data collection.

\section{Data Collection}

Patient interviews were conducted by one data collector using a structured questionnaire. The structured questionnaire was designed to assess socio-demographic factors such as marital status, socioeconomic status, age, gender, duration of past treatment; weight, monthly income, residence, co-morbidity and patient's contact status.

All registered MDR-TB patients were assessed individually. After developing rapport with each patient, psychological assessment was performed by a clinical psychologist using diagnostic and statistical manual of mental disorders, Fourth Edition (DSM-IV-TR) criteria for depression and Hamilton Depression Rating scale. ${ }^{22}$ Every patient was assessed at the time of registration.

\section{Tools/ Hamilton Depression Rating Scale Subsequent}

Hamilton depression rating scale (HAM-D) was used to assess depression among MDR-TB patients. The HAM-D scale consists of 20 questions according to the criteria of major depression as per the diagnostic and statistical manual of mental disorders, Fourth Edition, Text Revision (DSM-IV-TR). Total score ranges from 0 to 57 and indicate the severity of depression. In addition, the scoring is based on the first 17. It generally takes 15 - 20 minutes to complete the interview and score the results. It is a valid and reliable scale. Descriptive statistics were used to describe the data, i.e. mean and frequency along with percentages for categorical variables.

\section{Ethical Approval}

The study was approved by Research and Ethics Committee of the Institution, Kanpur, India.

\section{RESULTS}

A total of 130 MDR-TB patients were recruited for the study. Out of 130 patients, 93 (71.5\%) were male and 37 (28.5\%) were female patients. The majority of subjects were married $71(54.6 \%)$, while unmarried were 54 (41.5\%). The mean age of study subject was $29.45 \pm 14.49$ years with a male-tofemale ratio of 2.5: 1 . Most of the patients 89 (68.4\%) had history of past TB treatment for more than one year, while duration of less than one year was 41 (31.5\%). Patients belonging to rural area were $80(61.5 \%)$ and patients of urban area were $50(38.5 \%)$. Depression was not found in 6 (4.62\%) patients, whereas $124(95.3 \%)$ of the study participants were classified as depressive on the HAM-D scale, 65 patients $(50 \%)$ had mild depression, 26 patients (20\%) had moderate depression and 33 patients $(25.3 \%)$ were diagnosed with severe depression. The prevalence of depression was assessed in each group. Details given in Table 1.

\begin{tabular}{|c|c|c|c|c|c|c|c|c|}
\hline $\begin{array}{l}\text { Sl. } \\
\text { No. }\end{array}$ & \multicolumn{2}{|c|}{ Parameters } & $\begin{array}{c}\text { No Depression } \\
<10(\mathrm{~N}=6)\end{array}$ & $\begin{array}{c}\text { Mild } \\
10-13 \\
(\mathrm{~N}=65)\end{array}$ & $\begin{array}{c}\text { Moderate } \\
14-17 \\
(\mathrm{~N}=26) \\
\end{array}$ & $\begin{array}{c}\text { Severe } \\
>17 \\
(\mathrm{~N}=33)\end{array}$ & $\begin{array}{c}\text { Total } \\
\text { Numbers } \\
(n=130)\end{array}$ & $\%$ \\
\hline \multirow{6}{*}{1} & \multirow{6}{*}{$\begin{array}{c}\text { Age } \\
\text { (in Years) }\end{array}$} & $<19$ & 1 & 6 & 6 & 5 & 18 & $13.8 \%$ \\
\hline & & $20-29$ & 2 & 40 & 10 & 15 & 67 & $51.5 \%$ \\
\hline & & $30-39$ & 1 & 11 & 6 & 8 & 26 & $20 \%$ \\
\hline & & $40-49$ & 1 & 2 & 1 & 3 & 7 & $5.3 \%$ \\
\hline & & $50-59$ & 1 & 4 & 2 & 2 & 9 & $6.9 \%$ \\
\hline & & $>60$ & - & 2 & 1 & - & 3 & $2.3 \%$ \\
\hline 2 & \multicolumn{2}{|c|}{ Mean age (in Years) } & & 28.25 & 28.73 & 28.90 & & \\
\hline \multirow{2}{*}{3} & \multirow{2}{*}{ Sex } & Males & 2 & 48 & 17 & 26 & 93 & $71.5 \%$ \\
\hline & & Females & 4 & 17 & 9 & 7 & 37 & $28.4 \%$ \\
\hline 4 & \multicolumn{2}{|c|}{ Mean Weight (in Kg) } & & 44.57 & 43.03 & 40.63 & & \\
\hline \multirow{2}{*}{5} & \multirow{2}{*}{$\begin{array}{l}\text { Marital } \\
\text { Status }\end{array}$} & Unmarried & 1 & 31 & 9 & 13 & 54 & $41.5 \%$ \\
\hline & & Married & 5 & 30 & 17 & 19 & 71 & $54.6 \%$ \\
\hline
\end{tabular}




\begin{tabular}{|c|c|c|c|c|c|c|c|c|}
\hline & & Widow & - & 4 & - & 1 & & $3.8 \%$ \\
\hline \multirow{2}{*}{6} & \multirow[t]{2}{*}{ Residence } & Rural & 2 & 41 & 17 & 20 & 80 & $61.5 \%$ \\
\hline & & Urban & 4 & 24 & 9 & 13 & 50 & $38.4 \%$ \\
\hline \multirow[b]{2}{*}{7} & \multirow{2}{*}{$\begin{array}{l}\text { Duration of } \\
\text { previous anti- } \\
\text { tuberculosis } \\
\text { treatment }\end{array}$} & $<12$ Months & 3 & 26 & 8 & 4 & 41 & $31.5 \%$ \\
\hline & & $>12$ Months & 3 & 39 & 18 & 29 & 89 & $68.4 \%$ \\
\hline 8 & \multicolumn{2}{|c|}{$\begin{array}{l}\text { Mean duration of previous anti- } \\
\text { tuberculosis treatment } \\
\text { (in Months) }\end{array}$} & & 12.7 & 15.1 & 23.3 & & \\
\hline
\end{tabular}

Table 1. The Baseline Characteristics of Study Populations

\section{DISCUSSION}

Tuberculosis (TB) remains a leading infectious cause of morbidity and mortality throughout the world. India produces the maximum new cases of TB each year than any other country. Mental disorders are a diverse group of conditions varying in their presentation ranging from acuteto-recurrent-to-chronic, mild-to-severe, multiple disordersto-single illness, morbid or co-morbid conditions and in several other ways. ${ }^{23}$

The relationship between depression and chronic diseases can be bidirectional and people who suffer from chronic diseases report worse self-rated health as shown by Alves and Rodrigues through a population-based study conducted in Sao Paulo. ${ }^{24}$ When TB and depression coexist, the risk for developing comorbidities, suffering of patients and associated costs escalates.

This study was aimed at determining the prevalence of depression among MDR-TB patients and reported a prevalence of $95.38 \%$ among patients.

Islam A et al had done a study on 108 patients of tuberculosis to evaluate pattern of psychiatric illness among tuberculosis. They reported that depressive illness was the commonest $(39.83 \%, n=43)$ and others were anxiety (30.5\%), somatoform (10.1\%), psychotic spectrum disorder $(8.3 \%)$, personality disorder $(6.4 \%)$ and substance use disorder (3.1\%). ${ }^{25}$ The prevalence of depression in TB patients obtained in the present study is on the higher side and only depression parameter is analysed. Moussavi et al analysed data concerning people older than 18 years and reported the prevalence of depression in the whole sample was $3.2 \%$, but it reached $9.3 \%$ among those who reported diabetes, $10.7 \%$ among those who had arthritis and $18.1 \%$ among asthmatic individuals. ${ }^{26}$ There is evidence that patients with chronic respiratory and cardiovascular diseases present with higher prevalence of depression, but many studies have not adjusted the association by possible confounders. ${ }^{27-28}$

Issa BA et al done a study to know the depression comorbidity among 65 tuberculosis patients with the help of Patient Health Questionnaire (PHQ-9). They concluded that Eighteen $(27.7 \%)$ of the total patients had depression, comprising 14 (21.5\%) with mild depression and four (6.2\%) with moderate depression. This study also highlighted that 47 patients did not have the symptoms of depression. ${ }^{29}$ In the present study, $6.45 \%$ patients did not have the symptoms of depression. Ige $\mathrm{OM}$ et al had done a study to determine the prevalence of depression in 85 tuberculosis patients in comparison with non-tuberculosis controls, and its correlation with disease pattern with the help of GHQ-12. They reported that Depression was present in $45.5 \%$ of patients and $13.4 \%$ of controls $(\mathrm{P}<0.001)$. The prevalence of mild, moderate and severe depression were $13.6 \%, 11.4 \%$ and $20.5 \%$ respectively. ${ }^{30}$ The percentage of mild, moderate and severe depression in the present study are 50\%, 20\% and $25.38 \%$ respectively. Basu $G$ et al had done an observational study in a DOTS clinic to know the prevalence of depression in 110 tuberculosis patients. The Patient Health Questionnaire-9 was used to assess the depression and its severity. They concluded that $62 \%$ of the patients were depressed and majority of them belonged to the mild and moderate depression and $5.5 \%$ patients were severely depressed. ${ }^{31}$ The results of the above-mentioned study are comparable to the present study and majority of them have mild depression. Mrinalini Das et al had done a study to address the baseline psychiatric conditions of 45, HIVinfected MDR-TB patients with the Patient Health Questionnaire-9 (PHQ-9) tool. Of these seven (16\%) patients had depressive symptoms, while 38 did not have baseline depressive symptoms. ${ }^{32}$ The results in the present study are on higher side and the percentage of normal patients is $4.62 \%$. Adem A et al had done a study to assess the prevalence of depression in 222 tuberculosis patients and its relationship with regard to socio-demographic factors, disease characteristics, treatment factors and HIV infection. A pre-designed questionnaire, the Kessler which is prepared to be used for the rating depression and anxiety. This study has shown that $19.82 \%$ of tuberculosis patients were cases of depression and depression cases were $100 \%$ in older age group. ${ }^{33}$

Amreen and Rizvi $\mathrm{N}$ et al had done a study to determine the frequency of depression and anxiety among 100 (50 males and 50 females) tuberculosis patients with the help of Patient Health Questionnaire (PHQ-9) and Generalised Anxiety Disorder Questionnaire (GAD-7). They concluded that 56\% TB patients had moderate-to-severe level of depression and 65\% TB patients had moderate-to-severe level of anxiety. ${ }^{34}$ The percentage of moderate-to-severe depression in the present study are $45.38 \%$.

Vega $\mathrm{P}$ et al had done a retrospective case series of the first 75 patients who have received individualised MDRTB therapy in Lima, Peru. They have reported baseline prevalence of depression, anxiety and psychosis in $52.5 \%$, $8.7 \%$ and $0 \%$ patients respectively. 13 The present study showed higher percentage of depression in MDR-TB patients.

MA Sulheri et al conducted a study to know the prevalence of depression among tuberculosis patients and Beck's Depression Inventory-II was used for data collection of all patients. They have found that $80 \%$ were suffering from depression and among whom $45.8 \%$ were moderately and $37.5 \%$ were severely depressed leading to long stay in hospital and high costs of medicine. ${ }^{35}$ Our results are also comparable to the present study. Mirza I et al reported the 
prevalence of depression and anxiety in TB patients was about (47\%). ${ }^{36}$ Mehreen $S$ et al also had done a study to find out the frequency of depression at baseline (at the time of registration) in currently diagnosed MDR-TB patients and the emergence of depression during MDR-TB treatment in registered MDR-TB patients in PMDT. They had recruited 213 MDR-TB patients for the study. They stated that out of total patients, 139 (65.5\%) had depression at baseline and at the end of $1^{\text {st }}$ quarter only $47(33.81 \%)$ out of 139 still had depression and at the end of $2^{\text {nd }}$ quarter this number further decreased to $35(15.10 \%)$ and while the emergence of depression was $36 \%$ at the end of both 1 and 2 quarter. ${ }^{37}$ Our results are also comparable to the present study. Javaid et al had done a study to know the depression and its associated factors with Multidrug-Resistant Tuberculosis at Baseline among 289 patients. They found that the percentage of mild depression, moderate depression and severe depression were $63.1 \%, 30.3 \%$ and $6.46 \%$ respectively. They also concluded that depression was not found in 88 (30.45\%) patients. $^{38}$ The percentage of severe depression in the present study are $25.38 \%$. Baseline as well as ongoing monitoring of patient's mental health status is very important as it may facilitate the health care professionals, patients and their family members in proper management of a patient's condition during entire illness. Psychiatric co-morbidities are frequently associated with MDR-TB and their presence is not a contraindication to MDR-TB treatment. ${ }^{13}$

\section{CONCLUSION}

In the present study, 95\% of MDR tuberculosis patients were depressed at the time of registration. High rates of depression are likely related to long duration of treatment, social stigma, inadequate social support and the physiologic impact of chronic disease. The prevalence of depression was found to be more among males (86\%) than the female TB patients having $(71 \%)$ depression. Depression may also adversely affect the compliance to treatment and result in default, which in turn may have serious consequences of treatment failure and further extension in drug resistance. It is important to diagnose and treat depression in time to get the desired results of TB treatment.

\section{REFERENCES}

[1] Revised national tuberculosis control programme, 2017. http://www.tbcindia.gov.in

[2] Mahadev B, Kumar P, Agarwal SP, et al. Surveillance of drug resistance to anti-tuberculosis drugs in districts of Hoogli in West Bengal and Mayurbhanj in Orissa. Indian J Tuberculosis 2005;52(1):5-10.

[3] Paramasivan CN, Venkataraman P, Chandrasekaran V, et al. Surveillance of drug resistance in tuberculosis in two districts of South India. Int J Tuberc Lung Dis 2002;6(6):479-84.

[4] Ramachandran R, Nalini S, Chandrasekar V, et al. Surveillance of drug-resistant tuberculosis in the state of Gujarat, India. Int $\mathrm{J}$ Tuberc Lung Dis 2009;13(9):1154-60.

[5] Angst J, Ajdacic-Gross V, Rossler W. Classification of mood disorders. Psychiatr Pol 2015;49(4):663-71.
[6] Wells KB, Golding JM, Burnam MA. Psychiatric disorder in a sample of the general population with and without chronic medical conditions. Am J Psychiatry 1988;145(8):976-81.

[7] Regier DA, Goldberg ID, Taube CA. The de facto U.S. mental health services system: a public health perspective. Arch Gen Psychiatry 1978;35(6):685-93.

[8] Aydin IO, Ulusahin A. Depression, anxiety comorbidity and disability in TB and chronic obstructive pulmonary disease patients: applicability of GHQ-12. General Hospital Psychiatry 2001;23(2):77-83.

[9] Westaway MS, Wolmarans L. Depression and selfesteem: rapid screening for depression in black, low literacy, hospitalized TB patients. Social Science \& Medicine 1992;35(10):1311-5.

[10] Trenton AJ, Currier GW. Treatment of comorbid tuberculosis and depression. Primary Care Companion Journal of Clinical Psychiatry 2001;3(6):236-43.

[11] Moussas G, Tselebis A, Karkanias A, et al. A comparative study of anxiety and depression in patients with bronchial asthma, chronic obstructive pulmonary disease and tuberculosis in a general hospital of chest diseases. Annals of General Psychiatry 2008;7:7.

[12] Kunik ME, Roundy K, Veazey C, et al. Surprisingly high prevalence of anxiety and depression in chronic breathing disorders. Chest 2005;127(4):1205-11.

[13] Vega P, Sweetland A, Acha J, et al. Psychiatric issues in the management of patients with multidrug-resistant tuberculosis. Int J Tuberc Lung Dis 2004;8(6):749-59.

[14] Baghaei P, Tabarsi P, Dorriz D, et al. Adverse effects of multidrug-resistant tuberculosis treatment with a standardized regimen: a report from Iran. Am J Ther 2011;18(2):e29-e34.

[15] Aamir S, Aisha. Co-morbid anxiety and depression among pulmonary tuberculosis patients. J Coll Physicians Surg Pak 2010;20(10):703-4.

[16] Nathanson E, Gupta R, Huamani P, et al. Adverse events in the treatment of multidrug-resistant tuberculosis: results from the DOTS-Plus initiative. Int J Tuberc Lung Dis 2004;8(11):1382-4.

[17] Shin SS, Pasechnikov AD, Gelmanova IY, et al. Adverse reactions among patients being treated for MDR-TB in Tomsk, Russia. Int J Tuberc Lung Dis 2007;11(12):1314-20.

[18] Furin J, Mitnick C, Shin S, et al. Occurrence of serious adverse effects in patients receiving community-based therapy for multidrug-resistant tuberculosis. Int J Tuberc Lung Dis 2001;5(7):648-55.

[19] Peltzer K, Louw J. Prevalence of suicidal behaviour \& associated factors among tuberculosis patients in public primary care in South Africa. Indian J Med Res 2013;138:194-200.

[20] Grenard JL, Munjas BA, Adams JL, et al. Depression and medication adherence in the treatment of chronic diseases in the United States: a meta-analysis. J Gen Inter Medicine 2011;26(10):1175-82.

[21] Khan MA, Mehreen S, Basit A, et al. Predictors of poor outcomes among patients treated for multidrugresistant tuberculosis at tertiary care hospital in Pakistan. American-Eurasian Journal of Toxicological Sciences 2015;7(3):162-72. 
[22] Hamilton M. A rating scale for depression. Journal of Neurology, Neurosurgery and Psychiatry 1960;23:5662.

[23] Murthy RS. National Mental Health Survey of India 2015-2016. Indian J Psychiatry 2017;59(1):21-6.

[24] Alves LC, Rodrigues RN. Determinantes da autopercepçao de saude entre idosos do Município de São Paulo, Brasil. Rev Panam Salud Publica 2005;17(56):333-41.

[25] Islam AT, Md. Hoque A, Islam RT. Pattern of psychiatric illness among tuberculosis patients: an analysis in a tertiary care hospital of Bangladesh. International Journal of Applied Research 2015;1(13):763-6.

[26] Moussavi S, Chatterji S, Verdes E, et al. Depression, chronic diseases, and decrements in health: results from the World Health Surveys. Lancet 2007;370(9590):851-8.

[27] Ryu YJ, Chun EM, Lee JH, et al. Prevalence of depression and anxiety in outpatients with chronic airway lung disease. Korean J Intern Med 2010;25(1):51-7.

[28] Bremmer MA, Hoogendijk WJ, Deeg DJ, et al. Depression in older age is a risk factor for first ischemic cardiac events. Am J Geriatr Psychiatry 2006;14(6):523-30.

[29] Issa BA, Yussuf AD, Kurunga SI. Depression comorbidity among patients with tuberculosis in a university teaching hospital outpatient clinic in Nigeria. Mental Health in Family Medicine 2009;6(3):133-8.

[30] Ige OM, Lasebikan VO. Prevalence of depression in tuberculosis patients in comparison with nontuberculosis family contacts visiting the DOTS clinic in a Nigerian tertiary care hospital and its correlation with disease pattern. Mental Health in Family Medicine 2011;8(4):235-41.
[31] Basu G, Chatterjee C, Singh R, et al. Prevalence of depression in tuberculosis patients: an experience from a DOTS clinic. IJRRMS 2012;2(4):14-17.

[32] Das M, Isaakidis $P$, van den Bergh $R$, et al. HIV, multidrug-resistant $\mathrm{TB}$ and depressive symptoms: when three conditions collide. Glob Health Action 2014; 7: 24912.

[33] Adem A, Tesfaye M, Md. Adem M. The prevalence and pattern of depression in patients with tuberculosis on follow-up at Jimma University specialized hospital and Jimma health center. Medicine Science 2014;3(1):95568.

[34] Amreen, Rizvi N. Frequency of depression and anxiety among tuberculosis patients. Journal of Tuberculosis Research 2016;4:183-90.

[35] Sulehri MA, Dogar IA, Sohail H, et al. Prevalence of depression among tuberculosis patients. APMC 2010;4(2):133-7.

[36] Mirza I, Jenkins R. Risk factors, prevalence and treatment of anxiety and depressive disorders in Pakistan: systematic review. BMJ 2004;328(7443):794.

[37] Mehreen S, Khan MA, Basit A, et al. Frequency of depression in multidrug-resistant tuberculosis patients: an experience from a tertiary care hospital. Pak J Chest Med 2015;21(4):149-54.

[38] Javaid A, Mehreen S, Khan MA, et al. Depression and its associated factors with multidrug-resistant tuberculosis at baseline. J Depression \& Anxiety 2017;6:1-6. 